\title{
Experimental and numerical study of a directly PV-assisted domestic hot water system
}

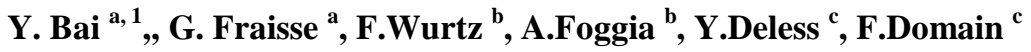 \\ ${ }^{a}$ Laboratoire Optimisation de la Conception et Ingénierie de l'Environnement, \\ Polytech Annecy-Chambéry, Campus Scientifique Savoie Technolac, \\ 73376 Le Bourget du Lac Cedex, France \\ Tel : +33479758895, Fax: +33479758144, \\ ${ }^{b}$ Grenoble Génie Electrique laboratoire, UMR 5269 INPG-UJF-CNRS \\ ENSIEG BP 46, 38402 ST MARTIN D'HERES Cedex, France \\ ${ }^{c}$ INES, Parc Technologique de Savoie Technolac, 50 avenue du Léman BP 258 \\ 73375 Le Bourget du Lac Cedex, France \\ baiyu_fanny@hotmail.com
}

\begin{abstract}
The solar domestic hot water (SDHW) system is the most highly developed system for use of solar energy. The developments for the thermal regulation of buildings should reinforce this trend given the significant reduction of heating needs. Currently, the design of these SDHW installations is well controlled and the system performance is reasonably good. The annual average solar fraction is consistent with expected level (between $60 \%$ and $70 \%$ ) according to a report of CSTB by evaluating 120 SDHW installations (Buscarlet and Caccavelli, 2006). However, the control mode of conventional SDHWs induces additional costs related to the consumption of auxiliaries and other risks of dysfunction of the circulation pump due to the temperature probes and controller setup which induces a lower annual productivity of solar collector (200 instead of $\left.400 \mathrm{kWh} / \mathrm{m}^{2}\right)$. From this point of view, the photovoltaic pumped system seems suitable since it eliminates the controller and temperature sensors. This paper focuses on an experimental and numerical study of the behavior of a PV-SDHW system, focusing on the start-up phase optimized through various electronic devices. A detailed model of a circulation pump was developed by considering a direct current (DC) circulation pump coupled with various electronic devices (linear current booster and maximum power point tracker). The developed models were then validated experimentally, to reveal the influence of the threshold solar radiation on the circulation pump start-up and the pump flow rate as a function of the solar radiation, and its effects on the annual energy performance of PVSDHW systems.
\end{abstract}

Keywords : Domestic hot water, photovoltaic, circulation pump, pump start-up, experimentation, simulation.

\footnotetext{
${ }^{1}$ Corresponding author: Tel. +852 344252 90;

E-mail address: baiyu_fanny@ hotmail.com
} 


\section{Introduction}

Reducing the greenhouse gas emissions is essential for limiting climate change. According to the report (Seghier, 2006), based on data from 41 industrialized countries, $36.8 \%$ decrease in emissions in the countries of Central and Eastern Europe, however, emissions decreased slightly between 1990 and 2001 . Still, the 2000-2001 periods showed an increase despite the commitments of the Kyoto Protocol. At the European level, the "triple 20 " goal for 2020 aims to reduce greenhouse gas emissions and energy consumption by $20 \%$, respectively and simultaneously incorporate $20 \%$ renewable energy into energy consumption.

In France, emission from the building sector accounts for $25 \%$ of the total emission, producing 120 million tons of $\mathrm{CO}_{2}$. Heating and domestic hot water (DHW) currently take the largest share of energy consumption in buildings ( $72 \%$ for heating and $11 \%$ for DHW). Thermal regulation has greatly reduced energy consumption for heating, which enlarges the share of DHW. Under these conditions, the role of SDHW is increasingly important in terms of constructing buildings with very low energy consumption.

A SDHW system reduces energy consumption and covers the demand of domestic hot water by $30-70 \%$. However, the results of monitoring 120 SDHW systems in France (Buscarlet et al., 2006) showed the dysfunction problems due to system over-sizing (cold water temperatures overestimated by about $4-5^{\circ} \mathrm{C}$ and the hot water draw profile), the incorrect setting of the controller, and temperature probes that are defective or not properly installed, as also highlighted in another report (CSTB, 2006), the latter problem could lead a disparity of the pump working time as well as a reduced system energy gain.

To minimize the shortages identified in the current installations, the photovoltaic (PV) - assisted operation is a potential measure. The first alternative approach is to replace the thermal solar collector in the conventional SDHW systems with PV modules. In this new system, hydraulic piping and heat exchangers are no longer used, which could reduce heat loss and improve heat transfer efficiency. Ghoneim et al. (Ghoneim et al., 2002) showed that this type of system can suffice for DHW needs, while the overall system cost is close to a conventional fuel based system. With the reduction in the cost of PV modules, the PV-SDHW system will be more competitive in the near future.

Another PV-assisted application is to couple the circulation pump directly with a PV module. The necessary PV module output power for this type of PV-SDHW is much lower than the previous configuration. The controller and the temperature sensors are not necessary in this system. Several studies have been conducted aiming to evaluate energy and economic performance through experimental and/or simulation results. Numerically, most 
of the studies are based on the use of very simplified circulation pump models. Other studies have improved performance by optimizing the system components or operating conditions.

Dayan (Dayan, 1997) studied different SDHW configurations, specially for the PV-assisted SDHW system. The simulation was performed with a flat-plat solar thermal collector of $3.185 \mathrm{~m}^{2}$, a tank of $400-1$ and an average daily hot water draw is about $300-1(12.2 \mathrm{~kg} / \mathrm{hr})$. An indirect natural convection using an external plate heat exchanger is considered in this study. The circulation pump in the solar loop is powered by a $20-\mathrm{Wp} \mathrm{PV}$ module. A pump model was developed, and the flow is determined from a third order polynomial function based on the voltage $V$ and hydraulic head $H$. This model was also used in others studies of PV pumping systems. (Kou et al., 1998; Cardinale et al., 2003; Martire et al., 2008;). The annual performance was analyzed numerically by estimating the solar fraction. The author concluded that the solar fraction obtained with the PV-SDHW system is lower compared with a standard SDHW system. Meanwhile, the low flow rate of $15 \mathrm{l} / \mathrm{h} . \mathrm{m}^{2}$ compared with standard flow rate $\left(50-701 / \mathrm{h} . \mathrm{m}^{2}\right)$, can maintain the stratification in the tank and therefore augment the gain of solar energy by 8 \% (Castell et al, 2010; Fanney and Klein, 1998; Kenjo, 2003; Knudsen and Furbo, 2004;). However, the circulation pump consumption is lower with PV power and the corrected solar fraction, which considers that the parasite energy used by the pump and the controller are very similar.

Al-Ibrahim (Al-Ibrahim et al., 1998) also conducted a numerical study on the optimization of a PV-SDHW system. The optimization procedure is divided into two phases. Initially, it aims to find the flow profile in relation to solar radiation, which maximizes the solar fraction. In the second phase, the goal is to select components from a range of pumps supplied by PV modules in order to obtain the pump torque/speed profile whose flow rate versus solar radiation profile approach the optimum. With this optimized approach, they found that the direct system (without heat exchanger) can achieve a solar fraction of about 0.7 versus 0.635 for an indirect system with a heat exchanger and a natural convection regime and 0.504 for an indirect system with a heat exchanger in a forced convection regime. Here, only the solar fraction is used as an estimation factor and other evaluation criteria (economic and environmental) were not considered. Finally, no experimental results are available for validating the models.

Cardinale et al. (Cardinale et al., 2003) conducted an experimental and numerical study of a PV-SDHW system. The system studied produces 500-1 of hot water per day for a family of four. An external heat exchanger was used to maintain the stratification in the storage tank with low flow. Two circulation pumps are powered directly by PV modules, one for the solar-heat exchanger loop and the other for the tank-exchanger loop. The system's performance is evaluated numerically using the TRNSYS simulation tool (Klein et al., 1998). A pump model has 
been developed with the flow also determined by the pump hydraulic head and voltage. The difference between this analysis and Dayan's is that in the latter, the cycle analysis method (life cycle analysis, LCA) was taken into account. They compared several configurations of PV-SDHW by varying the collector surface, the exchanger surface, and the weather conditions. They concluded that the best performance is achieved with the maximum thermal collector area and the maximum heat exchanger surface. However, the model does not take into account pump efficiency. They consider that the power supplied to the motor is fully transferred to the pump. In fact, for small power motors, motor losses are not insignificant and efficiency is often low ranging $15-40 \%$.

Macleod (Macleod, 1998) conducted a study on a PV-SDHW system using a 'solar boiler' provided by the manufacturer, Thermo Dynamics Limited. The system mainly includes two 6- $\mathrm{m}^{2}$ flat plate solar thermal collectors and a 450-1 storage tank with an internal coil heat exchanger. The subsystem consists of two polycrystalline PV modules (17 W and $20 \mathrm{~W}$ ), two DC motors, and centrifugal pumps manufactured by Procon. A linear current booster (LCB) is placed parallel between the PV module and the motor to ensure that the pump starts in low solar radiation. The different configurations depending on the power of the PV module and motor were analyzed experimentally. From the experimental results, the author found that the LCB can provide sufficient power to start the motor under the low solar radiation level, but during start-up, the performance of the LCB (ratio of power supplied to the motor and power output by the PV module) is low, between 65 and $70 \%$. For configurations using a high-power motor, the start takes place earlier with solar radiation at approximately $250-300 \mathrm{~W} / \mathrm{m}^{2}$. The performance of the LCB is slightly higher $(1-2 \%)$ than the other configurations.

Grassie et al. (Grassie et al., 2002) also conducted a study on a system with the PV-SDHW system aiming to provide a constant temperature at the collector output and to maintain thermal stratification in the tank. A numerical model was developed to determine the temperature at the collector output versus the pump flow rate, the collector area, the solar radiation, the temperature at the collector inlet, and the desired temperature at the collector outlet. To maintain this temperature, the power output of PV modules is modulated by varying the number of cells in series and thus the flow rate through the solar thermal collector. The results show that the predetermined temperature of the collector output is obtained for a sunshine level between 500 and $1000 \mathrm{~W} / \mathrm{m}^{2}$ when $66 \%$ of the PV module area is hidden. However, this model could be improved by taking into account the effects of the incidence angle and the viscosity of the fluid.

More concretely on the selection of the motor and pump types for directly coupled PV-assisted SDHW system, the use of a brushless DC motor is found to be more suitable which presents a high efficiency, high reliability and minimum maintenance requirement (Langridge et al., 1996; Kou et al., 1998; Firatouglu and Yesilata, 2004;). 
However, Brushless DC motors are available for low power applications. Concerning the pumps driven by DC motors, most of the studies indicated that the brushless DC motor coupled to a centrifugal pump was the most suitable combination (Anis, W.R., Metwally, H.M.B., 1994; Al-Ibrahim et al., 1998; Firatouglu and Yesilata, 2004;)

Most studies are based on the use of simplified models and experimental results which can not determine the level of annual performance on this type of PV-SDHW systems compared to a conventional system. This paper therefore focuses on the experimental and numerical studies of the solar circulation pump component supported by a PV module. The model was then used to evaluate the annual performance of the overall system.

\section{The PV-SDHW system}

\subsection{The experimental set-up}

An experimental set-up (Fig. 1) was built at the French National Institute for Solar Energy (INES). It comprises two flat plate solar thermal collectors (2 and $4 \mathrm{~m}^{2}$, Fig. 2) connected in parallel. The 400-1 storage tank is equipped an internal coil heat exchanger (Fig. 3). With the NAPAC acquisition system (which also controls the system) and the replacement of the circulation pumps, the standard SDHW systems and different configurations of the PV-SDHW system can be studied.

Figure 1: Experimental set-up at INES

Figure 2: Solar thermal collectors and PV module

Figure 3: Storage tank installed in the test space

Concerning the PV-SDHW systems, two DC circulation pumps were studied. The first is a standard DC circulation pump. The second is a commercialized solar circulation pump (Appendix I). They are both composed of a centrifugal pump and a brushless DC motor. The solar pump is designed to connect directly to the photovoltaic module. The integrated MPPT (maximum power point tracker) draws the maximum output from the PV module. In addition, the internal electronic control device and the capacitor start the pump at low solar radiation. Another electronic device, the LCB (linear current booster), was also tested to determine its effect during the start-up phase. The following three PV-SDHW configurations were studied (Fig. 4):

- $\quad$ Configuration I: PV + standard DC circulation pump (direct coupling);

- $\quad$ Configuration II: PV + solar circulation pump (direct coupling);

- Configuration III: PV + LCB + standard DC circulation pump (indirect coupling).

Figure 4: Configurations tested 
The resistances $R, R_{1}, R_{2}$ are used to determine the current in the circuits by measuring the voltage across the resistances.

\subsection{Experimental results and discussions}

The experimental results have allowed us to study the electrical, hydraulic, and thermal behaviors of different configurations.

\subsubsection{Electrical component}

The electrical behavior can be described in three steps during the circulation pump's start-up phase. In step 1, the voltage and current increase proportionally with the increase of solar radiation. In step 2, when sufficient voltage and current are supplied to the pump, the integrated control system starts to work. The current and voltage vary alternately, gradually increasing over time. The duration of this period depends on the intensity of the solar radiation. The motor begins to rotate in the third stage. However, at the beginning of this period, the pump flow rate is too low to be detected. After the start-up, the current varies in proportion to the solar radiation. This motor start-up process is also highlighted theoretical in the study realized by Suehrcke et al. (Suehrche et al., 1997). Fig. 5 shows the variation of the voltage and current for the solar circulation pump on a sunny day. With the MPPT, the pump start-up occurred earlier, at a solar radiation level of about $200 \mathrm{~W} / \mathrm{m}^{2}$ (this value varies up to $250 \mathrm{~W} / \mathrm{m}^{2}$ depending on the day studied) versus $350 \mathrm{~W} / \mathrm{m}^{2}$ for the standard DC circulation pump (config. I). The current in the pump varies proportionally with the solar radiation level, while the voltage remains almost constant between 14 and $16 \mathrm{~V}$. This value is directly related to the operation of the MPPT, which can deliver greater power to the solar circulation pump than that to the standard DC circulation pump with the same level of solar radiation.

Figure 5: Circulation pump voltage and current over time

For the configuration incorporating a LCB, Fig. 6 shows the current and voltage of the PV module and circulation pump for one day. It can be seen that the voltage of the PV module remains at $15 \mathrm{~V}$ (LCB reference voltage). The voltage and current at the pump vary greatly in the morning until 11:00 am because of cloud cover. When the pump rotation speed is high enough to generate enough electromotive force, the voltage across the pump is close to the LCB reference voltage. The LCB stops working when the voltage of the pump exceeds the LCB reference voltage. In the experimental configuration, the voltage across the pump is always lower than the LCB reference voltage and it remains at about $10 \mathrm{~V}$. The performance of the LCB (defined as the ratio of the power supplied to the circulation pump to the power delivered by the PV module) is relatively low during the pump start-up (60\%) and stopping. After the start-up, the efficiency reached 95\%. It decreases again when the pump stops working. 
Figure 6: Circulation pump electrical behavior

Fig. 7 shows the operating points of each configuration obtained by the intersection of the IV (IV represents 'Current' and 'Voltage' characteristics of the PV module with the characteristics of the circulation pump). The characteristics of the PV module are obtained from experimental measurements. The operating points of the solar circulation pump are close to the maximum power points of the PV module (Pmax) through the integration of the MPPT, while those in the standard DC circulation pump are relatively far from the Pmax, between 6 and 10 V. Regarding the configuration using a LCB, the voltage across the PV module remains constant and equls to the LCB reference voltage $(14.5 \mathrm{~V})$. The voltage across the pump increases with the solar radiation in this configuration.

Figure 7: Operating points of different configurations

\subsubsection{Hydraulic and thermal behaviors}

This section presents the experimental results concerning the profile of the circulation pump flow rate versus solar radiation, the threshold of solar radiation for pump start-up, and the temperature changes across the thermal collector.

For all configurations, the pump flow rate varies almost proportionally to solar radiation, as shown in Fig. 8 . The maximum flow rate in the solar circulation pump (config. II) is nearly the same as that in the standard DC pump with a LCB (config. III), except about 15 1/h.m² higher than that in the standard DC pump (config. I). It reduces the outlet temperature of the thermal collector. The heat losses are reduced and the annual energy performance could be augmented.

Figure 8: Comparison of the pump flow rate as a function of the solar radiation

The pump flow rate in the afternoon is much higher than in the morning with the same level of solar radiation. The difference is close to $10 \mathrm{l} /\left(\mathrm{h} . \mathrm{m}^{2}\right)$. Most studies of PV-SDHW systems such as the numerical studies of AlIbrahim and Kou (Al-Ibrahim, Kou et al., 1998) do not take it into account for this important phenomenon. The flow affects circulation pump efficiency in terms of overall losses (friction losses in the hydraulic pipe lines) and fluid characteristics (temperature, density, viscosity, etc.). According to several studies conducted on the characteristics of circulation pump (Henriksson et al., 2003; Alibert et al., 2007), viscosity is a major factor affecting on the performance of the circulation pump whose value is quite low (14\% maximum). The viscosity of the coolant can be calculated depending on the temperature and the percentage of anti-freeze (Guergen, 2005).

$v_{\text {cor }}=309 \cdot\left(37+T_{\text {fluid }}\right)^{-1.42} \operatorname{Exp}\left[1.1 \cdot \frac{\text { \%antifreeze }}{100} \cdot\left(256-T_{\text {fluid }}\right) \cdot 0.0001\right]$ 
With:

$v_{c o r}$, kinematic viscosity, $\left[\mathrm{mm}^{2} / \mathrm{s}\right]$

$T_{\text {fluid }}$, fluid temperature, $\left[{ }^{\circ} \mathrm{C}\right]$

The viscosity of the fluid decreases with increasing temperature, which results in less mechanical loss in the pump. The higher the viscosity, the lower the performance of the pump. This influence is particularly marked for centrifugal pumps. A factor related to the viscosity can be used (engineering toolbox) (Nally, 2007) to take into account this effect to calculate the pump efficiency.

The temperature difference between the collector's input and output is high for both the standard DC circulation pump (config.I and III) and the solar pump (config.II) $\left(15-20^{\circ} \mathrm{C}\right.$ ), as illustrated in Fig. 10. This discrepancy is much greater than the temperature differential in the classic matched flow rate system $\left(\Delta \mathrm{T}=5^{\circ} \mathrm{C}\right)$. This does not produce favorable results in terms of the heat loss of the thermal collectors.

Figure 9: Comparison of the temperature difference between the inlet and outlet of the solar thermal collector versus solar radiation

\section{Circulation pump dynamic model associated with electronic devices}

The experimental results have highlighted the need to develop a detailed model of the circulation pump if the goal is to accurately evaluate energy performance by numerical simulation. We therefore first developed the model of the standard DC circulation pump consisting of a brushless DC motor and a centrifugal pump. The model of the solar circulation pump was then obtained by integrating the MPPT model.

\subsection{Brushless motor model}

Regarding the electrical, electronic, and electromagnetic modeling of the brushless motor, the following hypotheses were taken into account:

- The magnetic circuit is not saturated, a condition necessary to consider the fluxes as linear functions of current;

- The magnetic circuit is fully laminated, so that only the windings (inducing and induced) are driven by currents. In addition, the current density can be considered uniform in the section of a single conductor;

- The consumption of the motor integrated with the control device is estimated using a resistor $R_{c}$ connected in series with the rotor.

The electrical diagram of the motor is shown in Fig. 10.

Figure 10: Equivalent electrical diagram of the brushless DC motor 
The electrical equation, linking the voltage $V_{m}$ across the motor armature and the armature current $I_{a}$ is written as:

$V_{m}=E_{m}+R_{a} I_{a}+L_{a} \frac{d I_{a}}{d t}$

With:

$R_{a}$, motor resistance, [' $\left.\Omega\right]$

$L_{a}$, motor inductance, $[\mathrm{H}]$

$E_{m}$, motor electromotive force, a function of the motor rotation speed,

$E_{m}=K_{V} \omega \quad[\mathrm{V}]$

With $K_{V}$, voltage constant, [V.s.rad ${ }^{-1}$ ]

The motor torque $T_{m}$ is proportional to the motor armature current $I_{a}$,

$T_{m}=K_{m} I_{a} \quad[\mathrm{Nm}]$

The mechanical equation including the rotation speed is written as:

$T_{m}=T_{L}+A_{1}+B_{1} \omega+J \frac{d \omega}{d t} \quad[\mathrm{Nm}]$

Where

$A_{l}$, motor static friction coefficient, [Nm]

$B_{1}$, motor viscous friction coefficient, $\left[\mathrm{Nm} \cdot \mathrm{rad}^{-1} . \mathrm{s}\right]$

$J$, motor moment inertia, $\left[\mathrm{kg} \cdot \mathrm{m}^{2}\right]$

The pump load torque can be expressed by the following equation:

$T_{L}=A_{2}+B_{2} \omega^{1.8} \quad[\mathrm{Nm}]$

With

$A_{2}$, torque constant of centrifugal pump, [Nm]

$B_{2}$, torque constant of centrifugal pump, $\left[\mathrm{Nm} \cdot \mathrm{rad}^{-1} \cdot \mathrm{s}\right]$

By combining equations (5) and (6), the motor torque can also be expressed as:

$T_{m}=A_{1}+B_{1} \omega+A_{2}+B_{2} \omega^{1.8}+J \frac{d \omega}{d t} \quad[\mathrm{Nm}]$

The coefficients $K_{v}$ and $K_{m}$ are close and it is possible to consider them as equal by ignoring the losses in the electromechanical power conversion.

The definition of the model takes into account the three steps identified during the test (Fig.11). The equations above are adapted to the three steps of the circulation pump operation. 
During Step 1, the electronic control device in the motor starts to run. The variation of current and voltage increases linearly as solar radiation increases. The changes in voltage and current obey the Ohm law. During this period, the tension and intensity levels are too low for the rotor to rotate. At the end of step 1, tension and intensity are sufficient to start the electronic control systems.

When sufficient voltage and current are supplied to the circulation pump, the electronic control device promoting the pump start-up begins to operate. Step 2 corresponds to the transient regime: voltage and current vary alternately. The pump rotation speed is zero as well as the load torque $\left(T_{L}=0\right)$,

Equation (2) becomes:

$R_{a} I_{a}+L_{a}\left(d I_{a} / d t\right)=V_{m}$

After starting (step 3), the derivative of the current is insignificant because $E_{m} \gg L_{a}\left(d I_{a} / d t\right)$. It is therefore assumed that this period corresponds to a steady state.

Equation (2) thus becomes:

$E_{m}+R_{a} I_{a}=V_{m}$

By combining equations (2) and (9), we obtain:

$K_{V} \omega+R_{a} I_{a}=V_{m}$

Equation (11) concerning the motor torque is written as:

$K_{m} I_{a}=A_{1}+B_{1} \omega+A_{2}+B_{2} \omega^{1.8}$

Parameters $R_{a}$ (resistance of the armature), $L_{a}$ (inductance), and $K_{v}$ (voltage constant) are obtained experimentally.

\subsection{Models of electronic devices}

In the experimental section, we showed that electronic devices such as the MPPT and LCB can improve the performance of the circulation pump toward the start-up. Thus, the models concerning these electronic devices were also developed.

\subsubsection{MPPT model}

The essential parameter for determining the output of the MPPT is the transformation ratio, which can be determined by the following relationship (Appelbaum, 1989):

$n=\frac{E}{2 V_{p p m} \eta_{M P P T}}+\left[\left(\frac{E}{2 V_{p p m} \eta_{M P P T}}\right)^{2}+\frac{I_{p p m} R_{a}}{V_{p p m} \eta_{M P P T}}\right]^{1 / 2}$ 
Where, $V_{P P M}$ and $I_{P P M}$ are the voltage and current at maximum power point, respectively. $E_{m}$ is the motor electromotive force without MPPT and the $\eta_{M P P T}$ represents MPPT efficiency.

Here we assume that the efficiency of the MPPT is equal to 0.5 for solar radiation, which is less than $200 \mathrm{~W} / \mathrm{m}^{2}$ and 0.9 for sunlight above this threshold because MPPT performance is not stable at low levels of solar radiation. The motor voltage and current are related to $V_{m}$ and $I_{m}$ by:

$V_{m}=\eta_{M P P T} n V_{p p m}$

$I_{m}=I_{p p m} / n$

\subsubsection{Model of linear current booster}

There are few numerical studies on LCB, and thus a model based on experimental results has been developed.

The voltage across the PV module remains constant when LCB works; the value is equal to the LCB reference voltage.

$V_{P V}=V_{\text {setpoint }}$

LCB efficiency is determined as the ratio between the power output of the PV module and the power delivered to the circulation pump.

$\eta_{L C B}=I_{m} V_{m} / I_{P V} V_{P V}$

A transformation ratio is used for $\mathrm{LCB}$ :

$I_{m}=n I_{P V}$

This ratio is determined as a function of the solar radiation in the present study:

$n=l_{1} G+l_{2}$

Where $l_{1}$ and $l_{2}$ are the coefficients obtained experimentally.

The pump voltage is written as:

$V_{m}=\eta_{L C B} V_{P V} / n$

\subsection{Centrifugal pump model}

The model of the centrifugal pump is presented in Dayan (Dayan, 1997). The pump flow rate is calculated according to the voltage $V$ across the circulation pump and the hydraulic head $H$ :

$\dot{m}=a+b H+c H^{2}+d H^{3}+e V_{m}+f V_{m}{ }^{2}+g V_{m}{ }^{3}+h H V_{m}+i H V_{m}{ }^{2}+j H^{2} V_{m}+k H^{2} V_{m}{ }^{2} \quad\left[\mathrm{~kg} . \mathrm{s}^{-1}\right]$

The coefficients used in equation (20) are determined experimentally. 


\subsection{Model validation}

The models developed have been implemented in the TRNSYS environment (Klein S et al., 1996) in order to simulate a complete PV-assisted SDHW system. Firstly, it is important to validate the models before establishing a complete system. A comparison is presented in the following paragraph between the simulation results of the circulation pump model and the experimental results with different configurations.

The simulation results are compared with experimental data during a sunny day for the solar circulation pump. Fig. 12 and Fig. 13 show the voltage and current of the solar circulation pump. The difference between the calculated and the measured current is greater, as shown in Fig. 12. In the morning, between $\mathrm{t}=12,000 \mathrm{~s}$ and $\mathrm{t}=$ $16,000 \mathrm{~s}$, the relative error varied between $3 \%$ and $-10 \%$. The numerically calculated voltage shows the same trend but the errors are smaller $( \pm 5 \%)$.

Figure 12: Comparison of calculated and measured current of the solar circulation pump

Figure 13: Comparison of calculated and measured voltage of the solar circulation pump

Fig. 14 shows the changes in the pump flow rate over time. Compared the results from the simulation with experimental data, the greatest difference is found in the early morning ( $t=0 \mathrm{~s}$ to $\mathrm{t}=40,000 \mathrm{~s}$ ) because of the unstable operation of the circulation pump as it starts up. In addition, under the low solar radiation condition, the MPPT performance is low and varies much more. This gap tends to decrease when the sun rises.

Figure 14: Comparison of calculated and measured flow rate in the solar circulation pump

In the experimental section, we have shown that, for the same solar radiation, there is, a difference in the pump flow rate between the morning and afternoon because of the change in fluid viscosity. In the circulation pump model, the effect of viscosity in the calculation of the pressure drop coefficient of the solar loop has been considered. An equation incorporating viscosity is used to calculate the pump rotation speed:

$Q_{\text {col }}=Q_{\text {colsimu }}\left(C_{1} v_{\text {cor }}+C_{2}\right) \quad[1 / \mathrm{h}]$

With $C_{1}$ and $C_{2}$ the coefficients related to the viscosity, obtained experimentally. The effect of viscosity on the pump flow rate is correctly considered, as shown in Fig. 15.

Figure 15: Comparison of calculated and measured flow rate versus solar radiation

\section{Evaluation of the system's annual performance}

After validating the circulation pump model, we compared numerically annual energy performance of the PV SDHW systems with conventional systems (on-off, variable flow). The configurations studied were:

(1) On-Off, collector flow rate, 50 1/(h.m²) 
(2) Matched flow rate system with $\Delta \mathrm{T}=5{ }^{\circ} \mathrm{C}$ (between inlet and outlet of the solar thermal collector), maximal flow rate 50 l/h.m²

(3) Matched flow rate system with $\Delta \mathrm{T}=9{ }^{\circ} \mathrm{C}$, maximal flow rate, $50 \mathrm{l} / \mathrm{h} \cdot \mathrm{m}^{2}$

(4) Matched flow rate system with $\Delta \mathrm{T}=13{ }^{\circ} \mathrm{C}$, maximal flow rate, $50 \mathrm{l} / \mathrm{h} \cdot \mathrm{m}^{2}$

(5) Matched flow rate system with $\Delta \mathrm{T}=17^{\circ} \mathrm{C}$, maximal flow rate, $50 \mathrm{l} / \mathrm{h} \cdot \mathrm{m}^{2}$

(6) PV-SDHW: direct coupling with a standard DC circulation pump

(7) PV-SDHW: direct coupling with a solar circulation pump

(8) PV-SDHW: indirect coupling with a standard DC circulation pump and a LCB

The following hypotheses are considered:

- $\quad$ Location: Lyon-Satolas

- Solar collector surface: $6 \mathrm{~m}^{2}$

- $\quad$ Storage tank capacity: 400-1

- $\quad$ DHW draw, 200 1/day

- Cold water temperature: monthly values used in French Thermal Regulation (Thermal Regulation 2005)

- Integrated auxiliary heater: $3 \mathrm{~kW}$ (control function: off-peak time $\& T_{\text {set-point }}<55^{\circ} \mathrm{C}$ )

Fig. 16 shows the different annual energy consumption values. The matched flow rate system with a $\Delta \mathrm{T}=5^{\circ} \mathrm{C}$ presents the lowest consumption of the auxiliary heater. The PV-SDHW system using a standard DC circulation pump, which consumes slightly more than $2,000 \mathrm{kWh}$ annually, is the least efficient. The consumption of the PV-SDHW system with the solar circulation pump is between the matched flow rate systems with $\Delta \mathrm{T}=9^{\circ} \mathrm{C}$ and with $\Delta \mathrm{T}=13{ }^{\circ} \mathrm{C}$. This is logical because the temperature difference between the inlet and outlet of the collector for the solar pump is about $11^{\circ} \mathrm{C}$ (Fig. 9). However, with the PV-SDHW, the circulation pump uses the electricity generated by the PV module and there is no controller. The total consumption of the system with the solar circulation pump is therefore lower than the matched flow rate system, even for the most efficient consumption $\left(\Delta \mathrm{T}=5{ }^{\circ} \mathrm{C}\right)$. The system with a LCB also shows a low total consumption compared to the on-off system, but it is not the best solution.

Figure 16: Comparison of the energy consumption of different SDHW configurations

The solar fraction (ratio of energy supplied by the solar part at the heat exchanger and the total system load energy), the most favorable is obtained with the matched flow rate system with $\Delta \mathrm{T}=5{ }^{\circ} \mathrm{C}(0.61)$. When the temperature difference increases, the solar fraction decreases. The solar fraction for the PV-SDHW system with 
a standard DC circulation pump is the lowest since it starts relatively late compared to the other PV-SDHW systems. The savings rate is defined as follows:

$F_{\text {sav }}=1-E_{\text {aux }} / E_{\text {conv }}$

With,

Eaux, auxiliary heating consumption, including the parasitic energy for the collector loop (circulation pump and the control unit), [kWh];

Econv, energy consumption of a conventional system without the solar component, [kWh].

The highest savings rate (0.59) is obtained with the PV-SDHW system using a solar pump because of the photovoltaic combination and the removal of the controller. From this point of view, the system with the solar pump is more advantageous than the matched flow system with a $\Delta \mathrm{T}$ of $5^{\circ} \mathrm{C}$.

However, the absence of controller in the PV-SDHW systems can lead to cooling the storage tank in the early morning and late afternoon. The heat losses in the morning (7:00-9:00 am) and late afternoon (5:00-7:00 pm) were estimated. They are determined as a percentage of the solar energy and correspond to a period when the tank is cooled by the solar heat exchanger. The losses in the morning with the standard DC circulation pump are almost nil because of a relatively late start-up. The solar circulation pump presents the greatest heat loss in the morning (about 1.9\%), but this configuration is the most powerful over the year as shown in Fig.16. The system with LCB presents heat losses in the afternoons that are somewhat higher than with other systems. The heat losses decrease as the temperature difference increases for the matched flow rate systems.

\section{Conclusions}

Different PV-assisted SDHW configurations were studied experimentally and numerically based on a developing new circulation pump model. The experimental results showed that the solar circulation pump is more efficient than the standard circulation pump which start-up late in the morning at a solar radiation of $350 \mathrm{~W} / \mathrm{m}^{2}$. However, the design of solar still needs to optimize because of the excessive output-input temperature difference at the collector. It is also necessary to develop a detailed circulation pump model regarding the correct phase and behavior of the start-up and between morning and afternoon, to precisely assess the energy performance through simulation.

A model of the circulation pump was developed considering the three start-up steps and integrating the model of the electronic devices such as MPPT and LCB. The results of the simulations are in a good agreement with the experimental values. The greatest differences are often occurred early in the morning during start-up. During this 
period, the practical behavior of the circulation pump is not stable because of the control devices integrated in the pump. Regarding the flow profile depending on solar radiation, the model accurately represents the difference between morning and afternoon with the consideration of viscosity change.

Regarding the annual energy performance, the PV-SDHW system with a solar circulation pump has the better performance compared with traditional systems (on-off and matched flow rate systems) and other PV-SDHW configurations. The annual consumption of auxiliary energy (circulation pump and controller) is deleted by coupling photovoltaic with other devices such as the LCB and MPPT, which amounts to approximately 100 $\mathrm{kWh}$. In terms of auxiliary heating consumption in the storage tank, the system using a solar pump reduces $7.5 \%$ consumption compared to the system with an on-off controller. Finally, the absence of a controller is not very harmful concerning heat loss at the beginning and end of the day. Also, controlling solar radiation input should improve the performance of in-situ solar installations with the feature of greater simplicity, lower risk of failure, and lower overall energy consumption.

\section{Appendix I}

\section{Characteristics of different types of circulation pump}

\begin{tabular}{|l|c|c|c|}
\hline \multicolumn{1}{|c|}{ Characteristics } & $\begin{array}{c}\text { Standard } \\
\text { AC circulation pump }\end{array}$ & $\begin{array}{c}\text { Standard } \\
\text { DC circulation pump }\end{array}$ & $\begin{array}{c}\text { Solar } \\
\text { circulation pump }\end{array}$ \\
\hline Motor type & AC motor & Brushless DC motor & Brushless DC motor \\
\hline Pump type & Centrifugal pump & Centrifugal pump & Centrifugal pump \\
\hline Operating voltage $(\mathrm{V})$ & 230 & $8-24$ & $8-24$ \\
\hline Operating current $(\mathrm{A})$ & 0.28 & $0.25-1.50$ & $0.20-1.46$ \\
\hline Head pressure $(\mathrm{kPa})$ & 30 & $0-38$ & $0-38$ \\
\hline Speed control & 3 speed & 5 speed & Automatic \\
\hline Built-in condenser $(\mu \mathrm{F})$ & 1.6 & 1,000 & 4,700 \\
\hline Design optimization & $\begin{array}{c}\text { Self-priming } \\
\text { (at the pump) }\end{array}$ & Microprocessor & $\begin{array}{c}\text { MPPT \& } \\
\text { microprocessor }\end{array}$ \\
\hline Power $(\mathrm{W})$ & 60 (maximal) & $3-35$ & $5-37$ \\
\hline
\end{tabular}

\section{Acknowledgments}

We wish to thank the APS and CNRS for funding the experimental set-up and the doctoral scholarship.

\section{References}

Alibert. J., et al., 2007. Efficiency advantages in Vane, Piston and Gear Pumps- What high VI Hudraulic Fluids

Can Do for you. $5^{\text {th }}$ International Fluid power conference (IFK) Euro-congress, Germany, 14 p.

Al-Ibrahim, A. M., et al., 1998. Design Procedure For Selecting An Optimum Photovoltaic Pumping System In a Solar Domestic Hot Water System. 64 (4-6): pp.227-239. 
Appelbaum. J., et al., 1989. The operation of permanent magnet DC motors powered by a common source of solar cells. IEEE Transactions on Energy Conversion 4(NO.4): pp.635-642.

Buscarlet, C. and D. Caccavelli., 2006. Suivi et évaluation énergétiques du plan soleil - Chauffe-eau solaire individuels: $10 \mathrm{p}$.

Buscarlet, C., CSTB, 2006. Plan soleil, catalogue des défauts des installations de chauffe-eau solaires individuels: $31 \mathrm{p}$.

Cardinale, N., et al., 2003. Economic optimization of low-flow solar domestic hot water plants. Renewable Energy 28(12), pp. 1899-1914.

Castell.A., et al., 2010. Dimensionless numbers used to characterize stratification in water tanks for discharging at low flow rates.

Dayan, M., 1997. High performance in low-flow solar domestic hot water systems. Master of Science. Thesis, University of Wisconsin-Madison, 224 p.

Firatoglu, Z., Yesilata, B., 2004. New approaches on the optimization of directly coupled PV pumping systems. Solar Energy 77, 81-93.

Fanney, A.H. and S.A.Klein., 1998. Thermal performance comparison for solar hot water systems subjected to various collector and heat exchanger flow rates. Solar Energy, 40, 1-11

Ghoneim, A. A., et al., 2002. Economic analysis of photovoltaic-powered solar domestic hot water systems in Kuwait. Renewable Energy 25(1): pp.81-100.

Grassie, T., et al., 2002. Design of a PV driven low flow solar domestic hot water system and modeling of the system collector outlet temperature. Energy Conversion and Management 43(8): pp.1063-1078. 
Guergen, M., 2005. Automatique des chauffe-eau solaire individuels grâce à l'alimentation photovolataique du circulateur. Mémoire du Master Ecotechniques - Université de Savoie, 108 p

Henriksson, L., et al., 2003. Improving pump efficiency and system performance by selecting the optimum fluid viscosity grade. The Eighth Scandinavian International Conference on Fluid Power, Finland, 11 p.

Kenjo, L., 2003. Etude du comportement thermique d'un chauffe-eau solaire à faible débit. Thèse de doctorat, Université de Nice-Sophia Antipolis. 274 p.

Klein S, A., et al., 1996. TRNSYS, Version 14.2 User manual Solar Energy Laboratory, University of Wisconsin.

Kou, Q., et al., 1998. A method for estimating the long-term performance of direct-coupled PV pumping systems. 64(1-3): pp.33-40.

Knudsen, S., Furbo, S., 2004. Thermal stratification in vertical mantle heat exchangers with application to solar domestic hot water systems. Applied Energy, Vol.78, pp. 257-272.

Langraidge, W., Lawrance, W., Wichert, B., 1996. Development of a photovoltaic pumping system using a brushless DC motor and helical rotor pump. Solar Energy 56, 151-160

Macleod, B. K., 1998. Evaluation of components in solar water heaters with photovoltaic powered pumps. Thesis, Dalhouse University Daltech, 50 p.

Metwally, H.M.B., 1994. Dynamic performance of a directly coupled PV pumping system. Solar Energy 53, 369-377.

Martire', T., et al., 2008. A simplified but accurate prevision method for along the sun PV pumping systems. Solar Energy 82, 1009-1020. 
Nally, M., 2007. Viscosity corrections to the pump curve. MC Nally Institute.7-8: 6 p.

Seghier, C., 2006. Les émissions de gaz à effet de serre dans les pays industrialisés sont reparties à la hausse. Actu-Environnement, $2 \mathrm{p}$

\section{Nomenclature}

$\begin{array}{lll}\mathrm{A}_{1} \quad \text { motor static friction coefficient } & {[\mathrm{Nm}]}\end{array}$

$\begin{array}{lll}\mathrm{A}_{2} & \text { Pump torque constant } & {[\mathrm{Nm}]}\end{array}$

$\mathrm{B}_{1} \quad$ Viscous friction coefficient $\left[\mathrm{Nm} \cdot \mathrm{rad}^{-1} . \mathrm{s}\right]$

$\mathrm{B}_{2} \quad$ Pump torque constant $\quad\left[\mathrm{Nm} \cdot \mathrm{rad}^{-1} \cdot \mathrm{s}\right]$

$\mathrm{C}_{1} \quad$ coefficients related to the viscosity, obtained experimentally [-]

$\mathrm{C}_{2} \quad$ coefficients related to the viscosity, obtained experimentally [-]

$\mathrm{Cp} \quad$ Specific heat $\quad\left[\mathrm{J}^{\mathrm{kg}} \mathrm{kg}^{-1} \cdot \mathrm{K}^{-1}\right]$

Cv Correction coefficient related to viscosity

$\begin{array}{lll}\mathrm{E}_{\mathrm{m}} & \text { Motor electromotive force } & \text { [V] }\end{array}$

$\begin{array}{lll}\mathrm{E}_{\text {aux }} & \text { Final energy consumption of the auxiliary heater } & {[\mathrm{kWh}]}\end{array}$

$\mathrm{E}_{\mathrm{conv}} \quad$ Final energy consumption of the system without solar component [kWh]

$\begin{array}{lll}\text { G Solar radiation } & {\left[\mathrm{W} / \mathrm{m}^{2}\right]}\end{array}$

$\mathrm{H} \quad$ Hydraulic head $\quad[\mathrm{m}]$

$\begin{array}{lll}\mathrm{I}_{\mathrm{a}} \text { Motor armature current } & \text { [A] }\end{array}$

$\begin{array}{lll}\text { IPPM } & \text { Output current at the maximum power operating point of the PV module (A) [A] }\end{array}$

$\begin{array}{lll}\mathrm{I}_{\mathrm{PV}} \quad \text { Output current of PV module } & \text { [A] }\end{array}$

J Moment of inertia $\quad\left[\mathrm{kg} \cdot \mathrm{m}^{2}\right]$

$\begin{array}{lll}\mathrm{K}_{\mathrm{m}} \quad \text { Torque constant } & {\left[\mathrm{Nm} . \mathrm{A}^{-1}\right]}\end{array}$

$\mathrm{K}_{\mathrm{v}} \quad$ Motor voltage constant [V.s.rad ${ }^{-1}$ ]

$\begin{array}{lll}\mathrm{L}_{\mathrm{a}} \quad \text { Motor inductance } & {[\mathrm{H}]}\end{array}$

$1_{1} \quad$ LCB (linear current booster) ratio $\quad[-]$

$1_{2} \quad$ LCB ratio $\quad[-]$

$\begin{array}{lll}\text { Qcol Flow rate in the solar loop } & {[1 / \mathrm{h}]}\end{array}$

$\begin{array}{lll}\mathrm{R}_{\mathrm{a}} \quad \text { Motor armature resistance } & {[\Omega]}\end{array}$

$\begin{array}{lll}\mathrm{T}_{\text {fluid }} \quad \text { Fluid temperature } & {[\mathrm{K}]}\end{array}$

$\begin{array}{lll}\mathrm{T}_{\mathrm{L}} & \text { Pump torque load } & {[\mathrm{Nm}]}\end{array}$

$\begin{array}{lll}\mathrm{T}_{\mathrm{m}} & \text { Electromagnetic torque } & {[\mathrm{Nm}]}\end{array}$

$\begin{array}{lll}\mathrm{V}_{\mathrm{sc}} & \mathrm{PV} \text { short-circuit voltage } & {[\mathrm{V}]}\end{array}$

$\begin{array}{lll}\mathrm{V}_{\text {setpoint }} \quad \text { LCB setpoint voltage } & {[\mathrm{V}]}\end{array}$

$\begin{array}{lll}\mathrm{V}_{\mathrm{m}} & \text { Motor voltage } & {[\mathrm{V}]}\end{array}$

$\begin{array}{lll}\mathrm{V}_{\mathrm{PV}} \quad \text { Photovoltaic voltage } & {[\mathrm{V}]}\end{array}$ 
$m \quad$ Mass flow rate

$\Delta \mathrm{T} \quad$ Temperature difference

\section{Indices}

$\begin{array}{ll}\text { aux } & \text { auxiliary } \\ \text { col } & \text { collector } \\ \text { conv } & \text { conventional } \\ \text { L } & \text { load } \\ \text { m } & \text { motor } \\ \text { PV } & \text { photovoltaic } \\ \text { sc } & \text { short circuit }\end{array}$

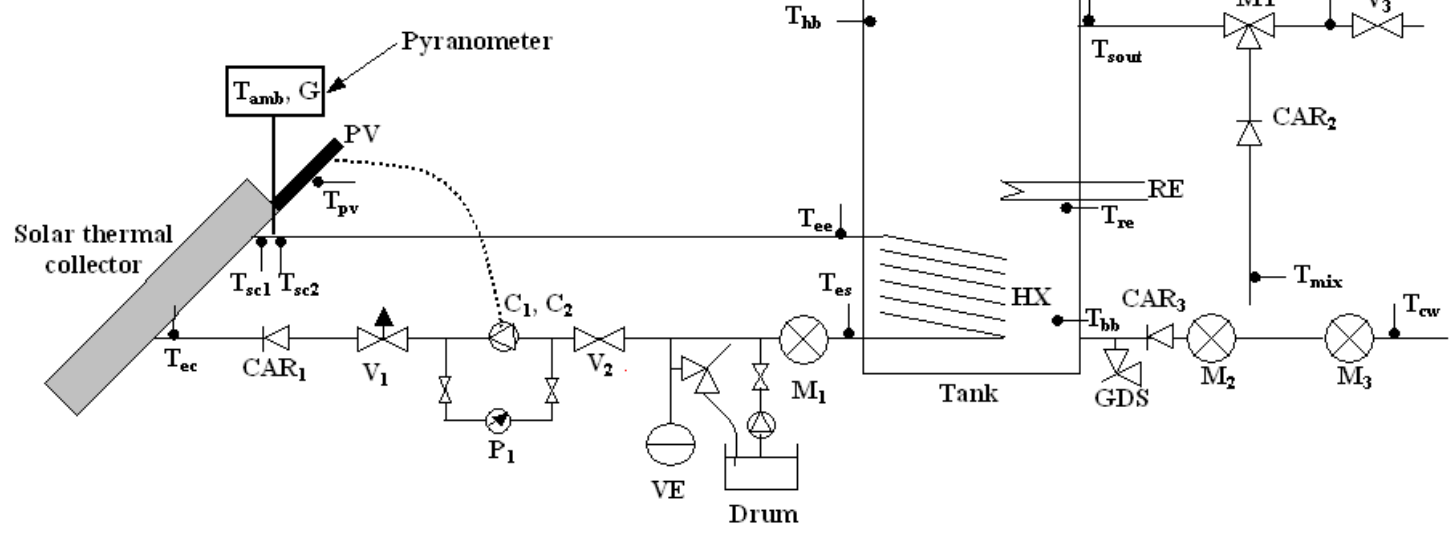

Figure 1: Experimental set-up at INES

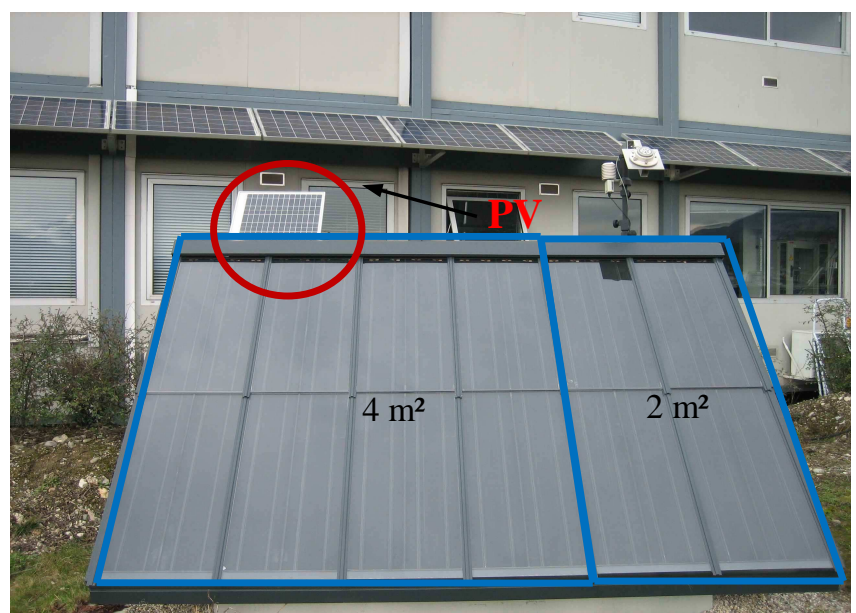

Figure 2 : Solar thermal collectors and PV module

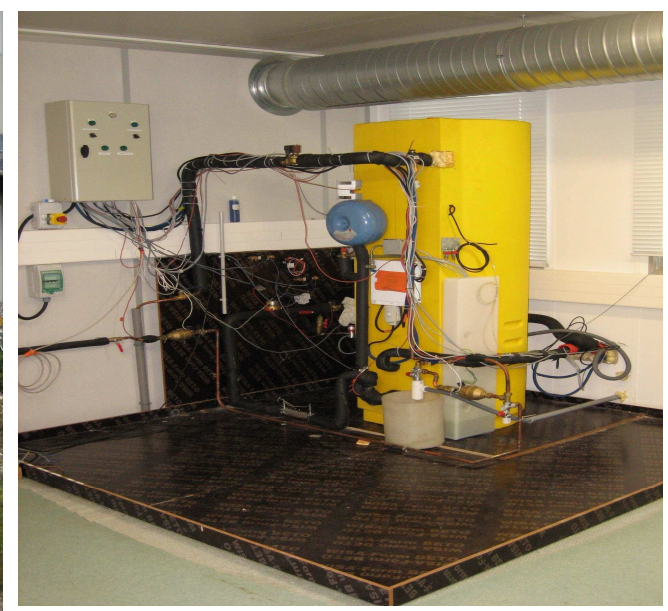

Figure 3 : Storage tank installed in the test space 


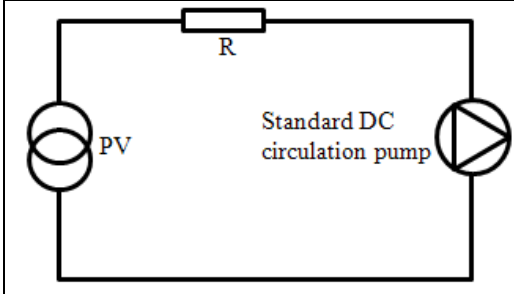

Configuration I: PV + standard DC circulation pump

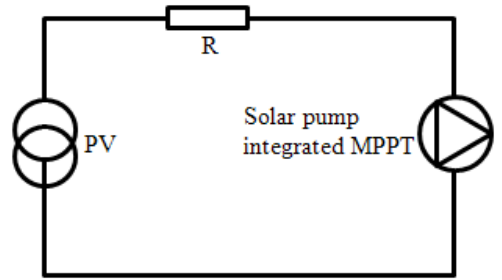

Configuration II: PV + solar pump integrated MPPT

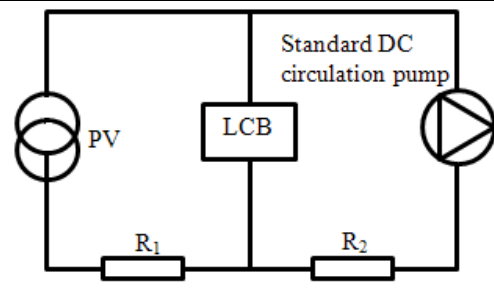

Configuration III: PV + LCB + standard DC circulation pump

Figure 4 : Configurations tested

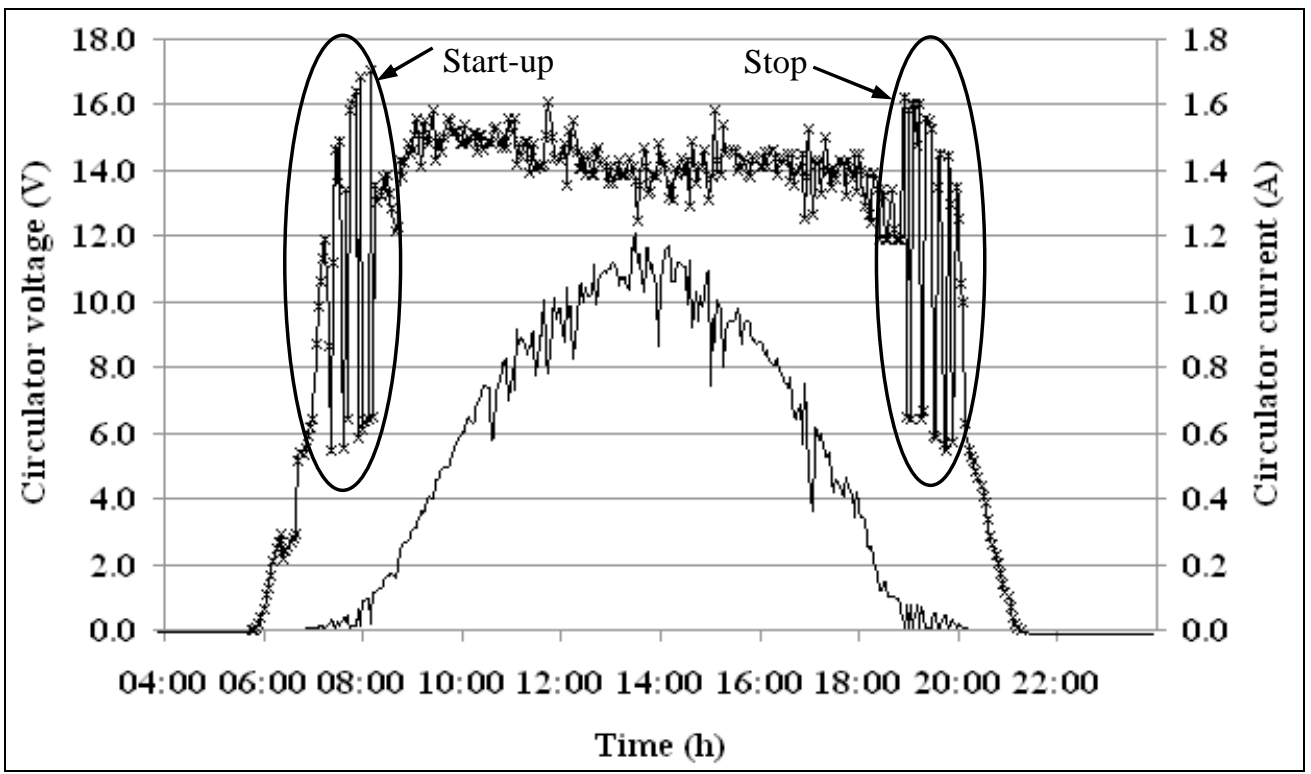

Figure 5 : Circulation pump voltage and current over time

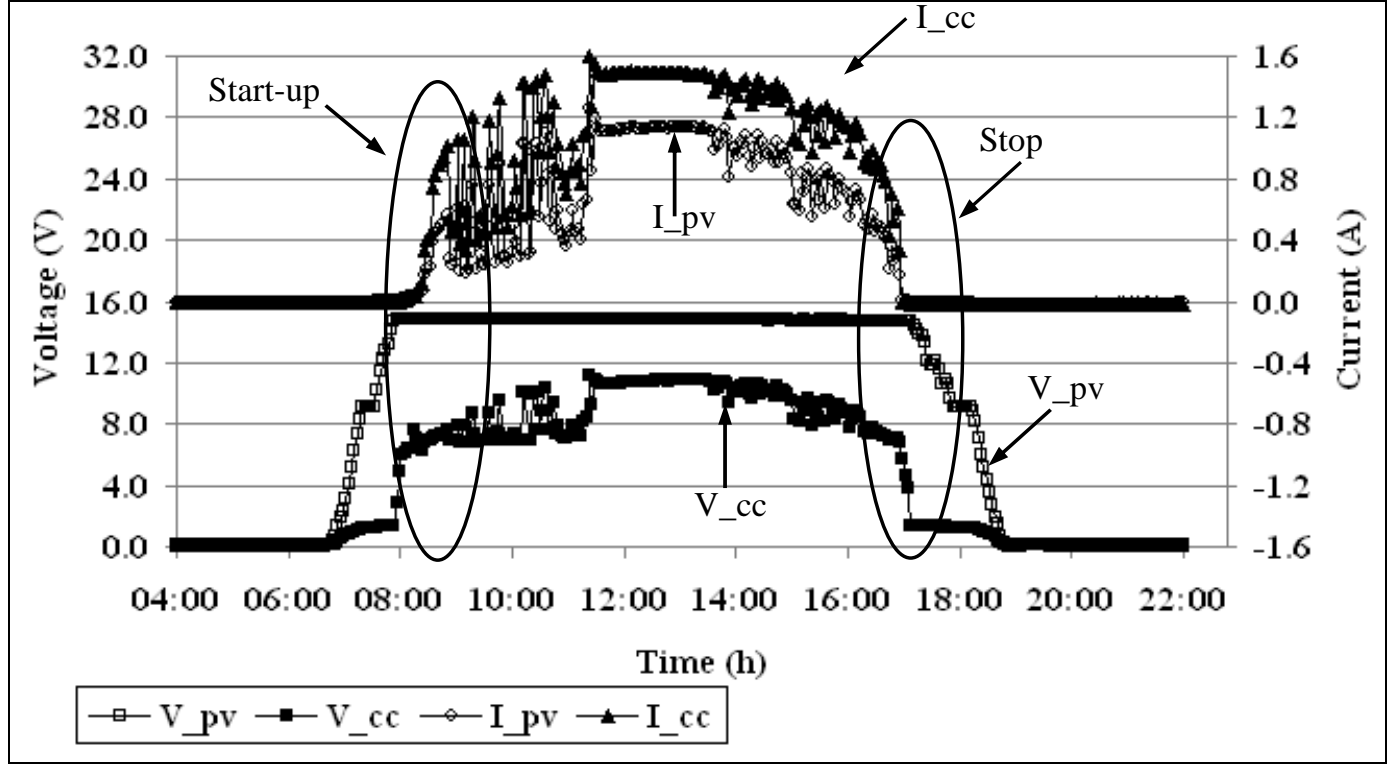

Figure 6 : Circulation pump electrical behavior 


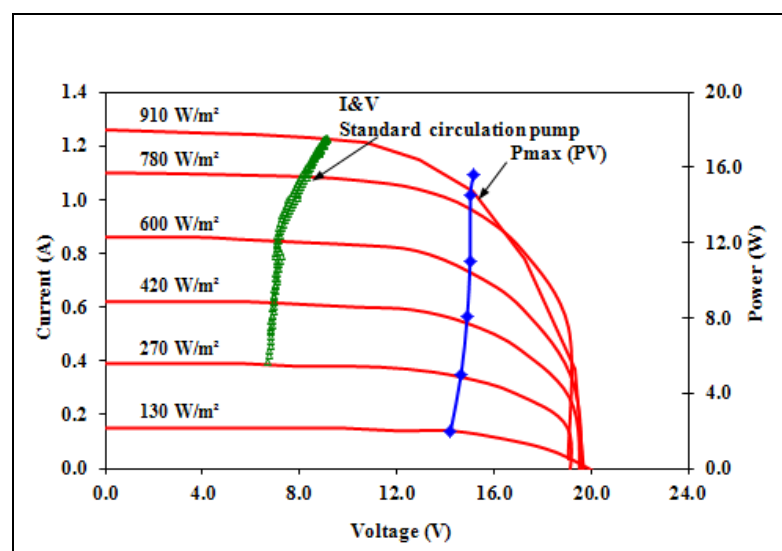

Configuration I

(standard DC circulation pump)

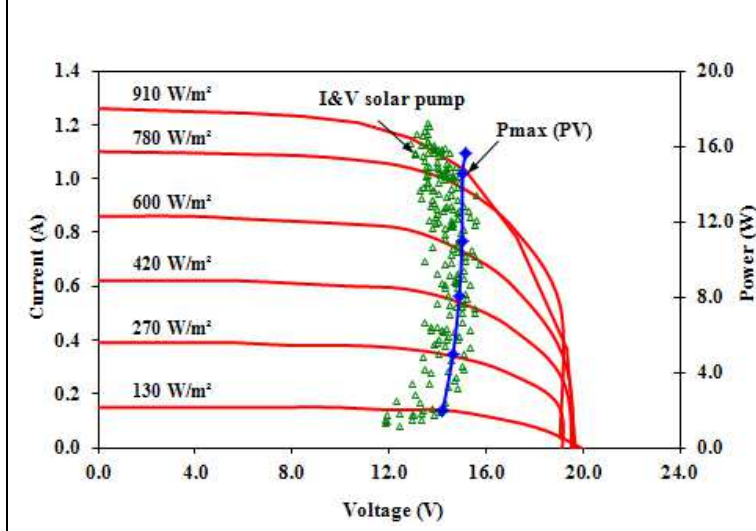

Configuration II

(solar circulation pump integrated MPPT)

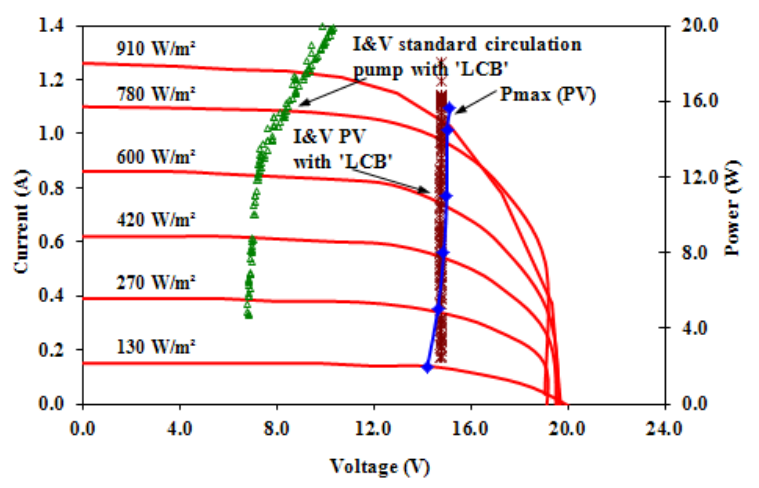

Configuration III

(Standard circulation pump + LCB)

Figure 7 : Operating points of different configurations

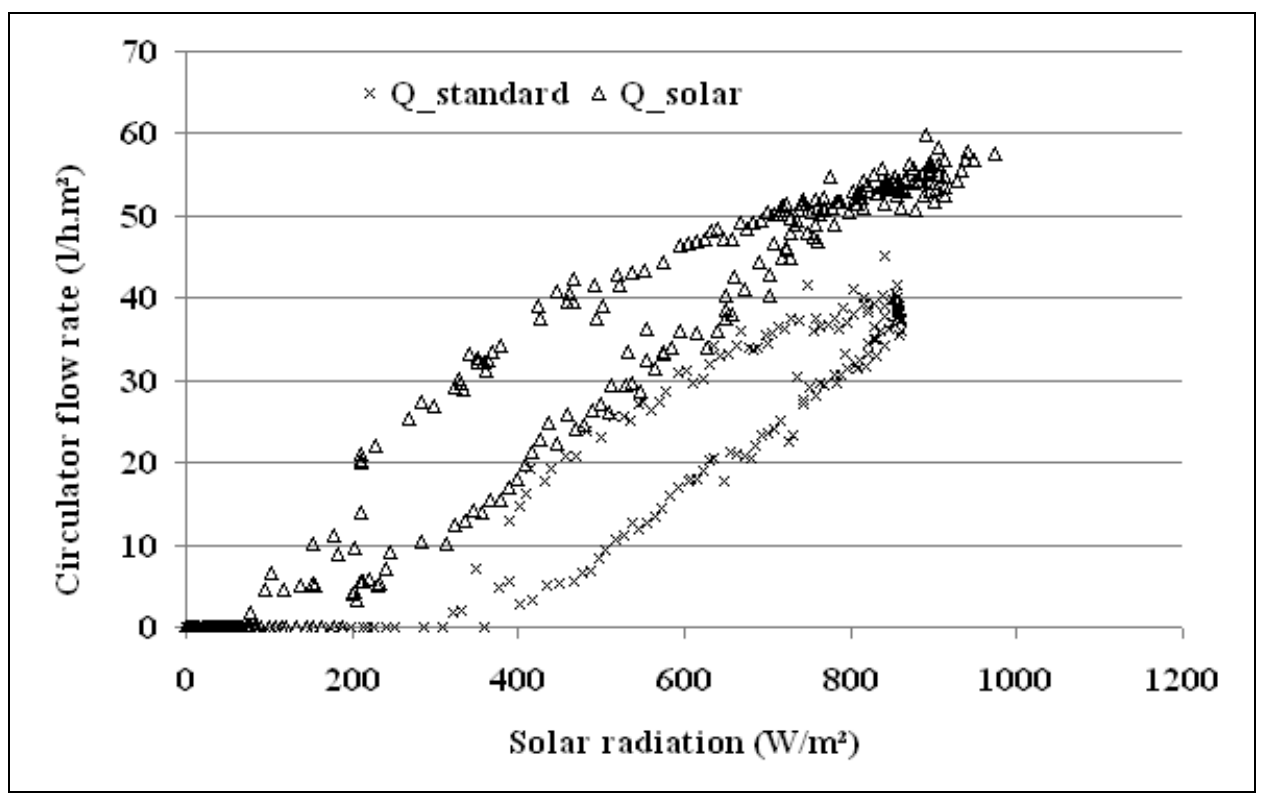

Figure 8 : Comparison of the pump flow rate as a function of the solar radiation 


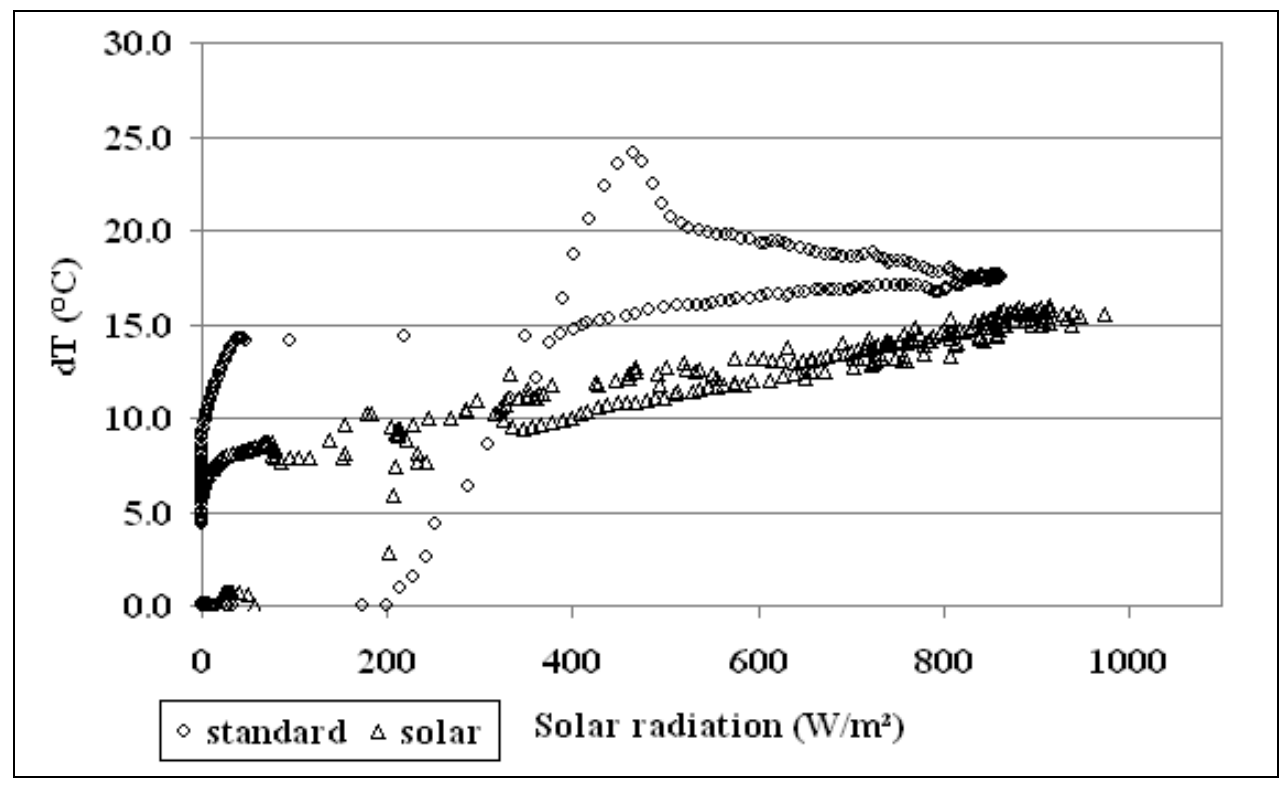

Figure 9 : Comparison of the temperature difference between the inlet and outlet of the solar thermal collector versus solar radiation

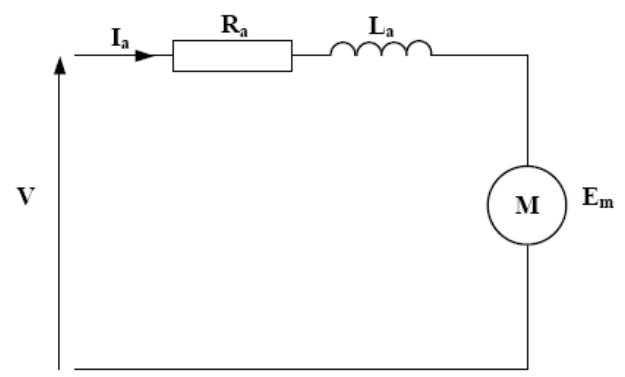

Figure 10 : Equivalent electrical diagram of the brushless DC motor

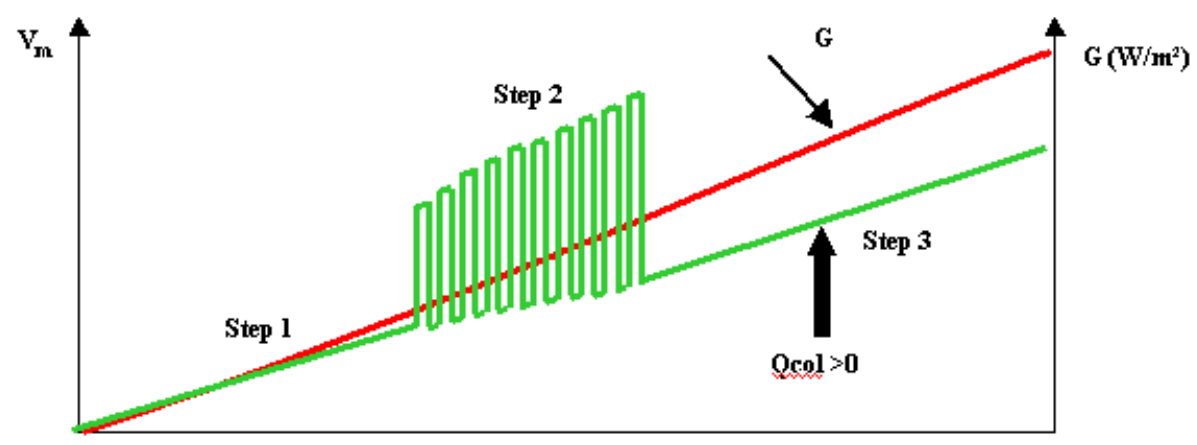

Figure 11 : Circulation pump operation steps 


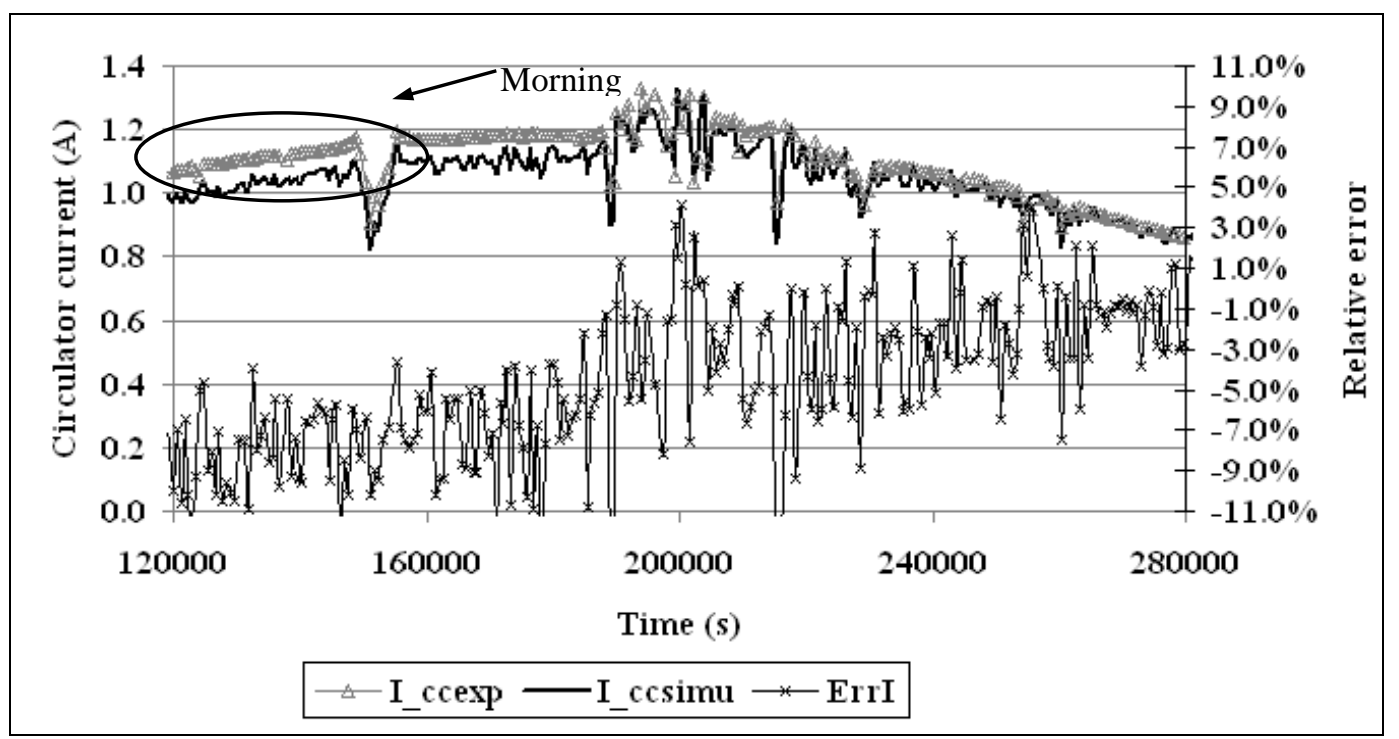

Figure 12 : Comparison of calculated and measured current of the solar circulation pump

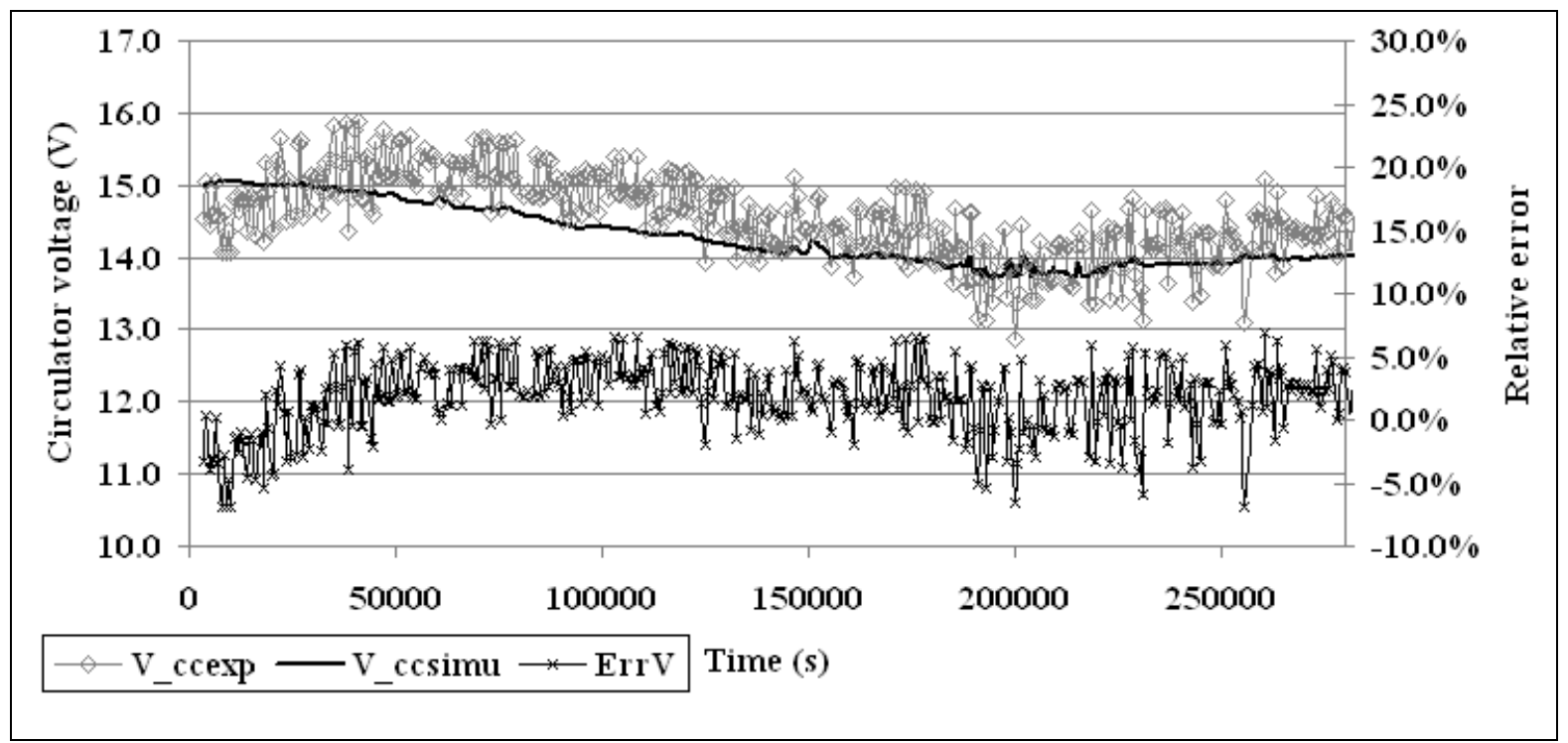

Figure 13 : Comparison of calculated and measured voltage of the solar circulation pump 


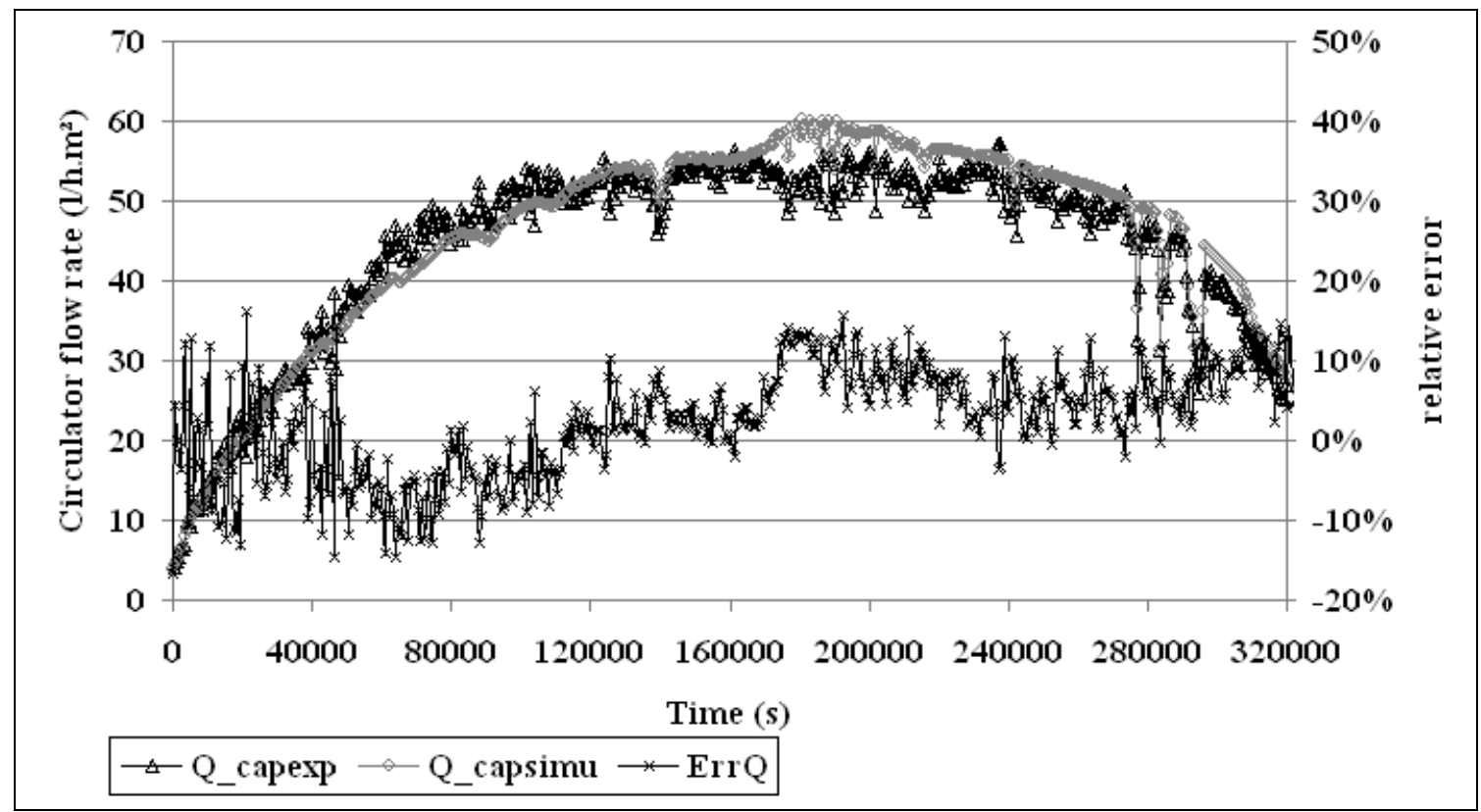

Figure 14 : Comparison of calculated and measured flow rate in the solar circulation pump

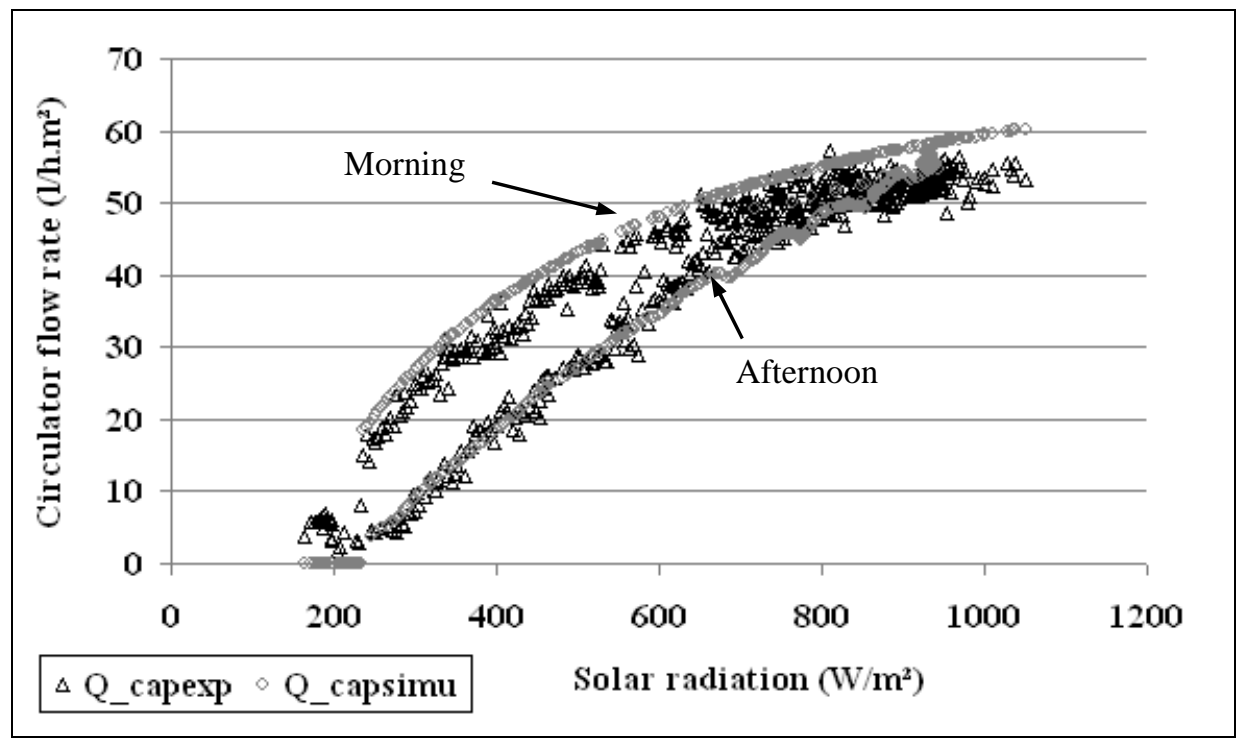

Figure 15 : Comparison of calculated and measured flow rate versus solar radiation 


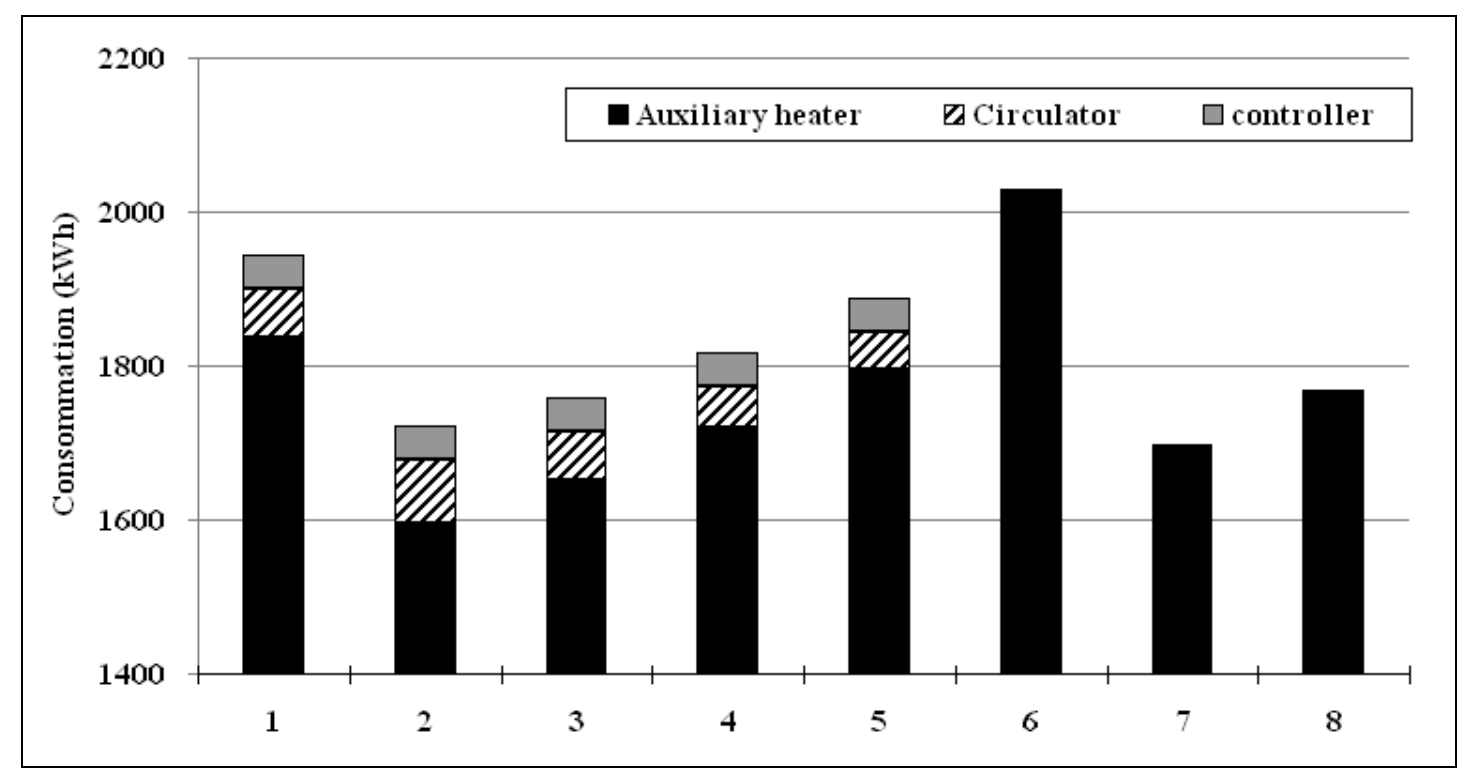

Figure 16 : Comparison of the energy consumption of different SDHW configurations 